\title{
Peptide 17, an inhibitor of YAP/TEAD4 pathway, mitigates lung cancer malignancy
}

\author{
Jirong Zhang, Yong Pan, Dehua Liao, Jingyi Tang, Dunwu Yao* \\ Department of Pharmacy, Hunan Provincial Tumor Hospital, Changsha 410006, China \\ ${ }^{*}$ For correspondence: Email: yaodunwumedchs@163.com
}

Sent for review: 3 April 2018

Revised accepted: 27 June 2018

\begin{abstract}
Purpose: To investigate whether and how peptide 17 affects lung cancer cells.

Methods: Human lung carcinoma cells, LLC and PC-9, were employed to study the therapeutic effect of peptide 17 on lung cancer. After exogenous expression of peptide 17, a co-immunoprecipitation experiment was used to examine the inhibitory effect of peptide 17. CCK8 assay was employed to assess the lung cancer cells' viability while clone formation assays were used to assess lung cancer cell proliferation. Colony number was also determined. The stimulatory effect of peptide 17 on lung cancer cell apoptosis was assessed by fluorescence-activated cell sorting (FACS).

Results: Peptide 17 efficiently disrupted the interaction between YAP and TEAD4 $(p<0.001)$, and decreased the expression of CTGF and Cyr61. In addition, lung cancer cell viability and proliferation significantly decreased $(p<0.001)$ in a time- and concentration-dependent manner. On the other hand, the proportion of apoptotic cells was significantly elevated with rising concentration of peptide 17.

Conclusion: Exogenous expression of peptide 17 activates Bc/2/Bax/caspase-9 signal and is responsible for its inhibitory effects on lung cancer cells. Thus, peptide 17 is a promising target drug in lung cancer treatment.
\end{abstract}

Keywords: Lung cancer, Yes-associate protein, Transcriptional enhancer activation domain 4 (TEAD4), Peptide 17, Apoptosis

\begin{abstract}
This is an Open Access article that uses a funding model which does not charge readers or their institutions for access and distributed under the terms of the Creative Commons Attribution License (http://creativecommons.org/licenses/by/4.0) and the Budapest Open Access Initiative (http://www.budapestopenaccessinitiative.org/read), which permit unrestricted use, distribution, and reproduction in any medium, provided the original work is properly credited.

Tropical Journal of Pharmaceutical Research is indexed by Science Citation Index (SciSearch), Scopus, International Pharmaceutical Abstract, Chemical Abstracts, Embase, Index Copernicus, EBSCO, African Index Medicus, JournalSeek, Journal Citation Reports/Science Edition, Directory of Open Access Journals (DOAJ), African Journal Online, Bioline International, Open-J-Gate and Pharmacy Abstracts
\end{abstract}

\section{INTRODUCTION}

Lung cancer, a potentially fatal disease, was first identified in 1761 [1]. Until 1929, investigators believed that lung cancer initiation was closely associated with smoking [2]. Other risk factors, such as radon gas, asbestos, air pollution, and genetic mutations, are also associated with the evolution of lung cancer $[3,4]$. Similar to other malignant tumors, lung cancer is eventually caused by activation of oncogenes or inactivation of tumor suppressor genes. Kirsten rat sarcoma (KRAS) and epidermal growth factor receptor (EGFR) genes are the most commonly mutated genes in lung cancer $[5,6]$. On the basis of the molecular knowledge of lung cancer, specifically targeted treatments besides traditional surgery or radiotherapy, promote positive therapeutic outcomes [7]. For example, various small molecule drugs have been designed to tackle all possible situations, such as gefitinib and erlotinib [8-10]. 
Recently, several studies have reported that yesassociated protein (YAP) played a pivotal role in lung cancer progression. YAP, a transcriptional co-activator, is the downstream effector of the Hippo pathway that suppresses tumor growth. Mechanistically, when the Hippo pathway is inactivated, YAP interacts with transcriptional enhancer activation domain (TEAD) family members to promote cellular proliferation and inhibit apoptosis $[11,12]$. Given the critical role of YAP in lung cancer, peptide 17, a promising inhibitor of YAP/TEAD4 signaling, was supposed to ameliorate the malignancy of lung cancer $[13,14]$.

\section{EXPERIMENTAL}

\section{Cell culture}

Human lung carcinoma cells, LLC and PC-9, were purchased from the Bena culture collection Co., Ltd (Jiangsu, China). Cells were cultured following the manufacturer's instructions. The cells were cultured with Dulbecco's modified Eagle's medium (DMEM), supplemented with 10 $\%$ FBS and $1 \%$ penicillin/streptomycin (Gibco, USA). Cells were incubated in a humidified atmosphere containing $5 \% \mathrm{CO}_{2}$.

\section{RNA extraction and reverse transcription polymerase chain reaction (RT-PCR) analysis}

mirVana miRNA kit (Takara, China) was used to extract total RNA from the LLC and PC-9 cells following the manufacturer's instructions Of note, the internal control that we used was U6 small RNA. For detection of connective tissue growth factor (CTGF / CCN2) and cysteine-rich angiogenic inducer 61 (Cyr61 / CCN1) mRNA expression, a PrimeScript RT reagent kit (Takara, Dalian, China) was used to synthesize the first-strand cDNAs. The expressions of CTGF and Cyr61 were quantified by RT-PCR Mixture assays (Takara). GAPDH was used as the internal control. The primers used for RT-PCR are shown in Table 1.

\section{Cell viability assay}

Lung cancer cells viability was assessed through a Cell Counting Kit-8 assay (CCK-8) according to the manufacturer's protocol (Dojindo; Tokyo,
Japan). Cells $\left(2 \times 10^{3}\right)$ were seeded into 96-well plates and incubated at $37^{\circ} \mathrm{C}$ for $24 \mathrm{~h}, 48 \mathrm{~h}$, or $72 \mathrm{~h}$ in a humidified chamber containing $5 \%$ $\mathrm{CO}_{2}$. Then, the CCK-8 solution $(10 \mu \mathrm{L})$ was added to each well, and the plates were incubated for $1 \mathrm{~h}$ at $37^{\circ} \mathrm{C}$. The absorbance at $450 \mathrm{~nm}\left(\mathrm{OD}_{450}\right)$ was measured in a microplate reader (Bio-Rad, USA).

\section{Western blot assays}

Expression of proliferative proteins, such as $\mathrm{Ki} 67$, was determined by western blot. The LLC and PC-9 cells were lysed with RIPA buffer. Primary antibodies, such as rat anti Ki67 (Santa Cruz, $1: 500)$, rat anti Bax (Sigma, $1: 1000)$, and mouse anti Bcl-2 (Santa Cruz, 1 : 1000), were integrated with the targeted protein by incubation at room temperature for 1-2 h. Horseradish peroxidase (HRP) the labelled secondary antibodies were used to detect the expression of $\mathrm{Ki67}$, Bax, and Bcl-2 through chemiluminescence, huamn $\beta$-actin was used as a loading control.

\section{Colony formation assay}

After transfection, $1 \times 10^{3}$ cells were seeded into a 6-well plate and cultured for $24 \mathrm{~h}$. Next, cells were cultured for 2 weeks in DMEM medium. Of note, DMEM should be supplemented with FBS at a final concentration of $10 \%$. The colonies were then washed with PBS three times. Methanol and $0.1 \%$ crystal violet were used to fixed and stain the colonies for $30 \mathrm{~min}$. The number of colonies with $>50$ cells were counted.

\section{Luciferase reporter assay}

Human TEAD4 3'-UTR, which contains the peptide 17 binding site, was amplified by PCR and cloned into the pGL3-control vector (Ambion) at the Nhel and Xhol sites. The resultant reporter plasmid was titled TEAD4-Wt-3'-UTR. For luciferase assays, LLC and PC-9 cells were cultured in 6-well plates and supplemented with peptide 17 (5, 10, 20 and $40 \mathrm{nM})$. The TEAD4Wt-3'-UTR reporter plasmid (100 ng/well) and the $\mathrm{pRL}-\mathrm{TK}$ luciferase reporters (25 ng/well) were transfected into the cells using lipofectamine 2000 (Invitrogen).

Table 1: Primers used for RT-PCR

\begin{tabular}{lcc}
\hline Genes & Forward primer & Reverse primer \\
\hline CTGF & 5'-CTGCCTGGGAAATGCTGCGAGGAGT-3' & 5'-GTTGGGTCTTGGGCCAAATGT - 3'. \\
Cyr61 & 5'-ACCGCTCTGAAGGGGATCT-3' & 5'-ACTGATGTTTACAGTTGGGCTG - 3' \\
GAPDH & 5'-GGAGCGAGATCCCTCCAAAAT-3' & 5'-GGCTGTTGTCATACTTCTCATGG -3' \\
\hline
\end{tabular}


Dual-Luciferase Reporter Assay kit (Promega, USA) was used to assay luciferase activity levels according to the manufacturer's instructions. Renilla-luciferase was used for normalization.

\section{Apoptosis assay}

Apoptosis Detection Kits (BioVision, Mountain View, CA, USA), based on Annexin V/PI staining, were used to examine apoptosis of the LLC and PC-9 cells. $1 \times 10^{6}$ cells were harvested and washed with PBS. Then, the cells were resuspended by binding buffer $(500 \mu \mathrm{L})$. Next, 5 $\mu \mathrm{L}$ of Annexin V/FITC and $1 \mu \mathrm{L}$ of $\mathrm{PI}$ were introduced into the cells. Flow cytometry analysis was subsequently used to examine the apoptotic cells (BD, USA).

\section{Co-immunoprecipitation experiments}

The LLC and PC-9 cells were harvested in immunoprecipitation (IP) lysis buffer supplemented with complete protease inhibitor cocktail (Sigma). The cell lysate was immunoprecipitated using anti-YAP or antiTEAD4 antibody (Sigma, $1: 1000$ ), and the proteins were separated by sodium dodecyl sulfate-polyacrylamide gel electrophoresis (SDSPAGE) followed by immunoblotting.

\section{Data analysis}

Data are presented as mean \pm standard deviation. Statistical analyses between two groups were performed using Student's t-test via SPSS 16.0 (SPSS Inc, Team EQX), while statistical analyses between multiple groups were performed using one-way analysis of variance followed by the least significant difference post hoc test. Differences with values of $p<0.05$ were regarded as statistically significant.

\section{RESULTS}

\section{Peptide 17 efficiently inhibited the interaction of YAP and TEAD4}

Given the important role of YAP signaling in lung cancer, we first examined the expression of YAP and TEAD4 in two lung cancer cell lines, LCC and PC-9. We found that the YAP/TEAD4 pathway was activated in both cancer cells. Next, the efficiency of peptide 17 in binding TEAD4 was tested. Peptide 17, at four different concentrations, was added to the LLC and PC-9 cells. Total protein was harvested, and the interaction of YAP and TEAD4 was verified. Coimmunoprecipitation results showed that peptide 17, a YAP analogue, could efficiently bind the protein TEAD4 in a concentration dependent manner. A luciferase reporter assay further demonstrated the efficiency of peptide 17 in binding TEAD4 (Figure $1 \mathrm{~A}$ ). The CTGF and Cyr61 genes, which are responsible for cellular proliferation and apoptosis, were both targets of the YAP/TEAD signal. Therefore, after exogenous expression of peptide 17, the expression of Cyr61 and CTGF was subsequently examined. Results showed that supplementation of the cells with peptide 17 inhibited their expression (Figure 1 B-C). Consequently, peptide 17 could be a new method of targeting malignant proliferation of lung cancers cells.
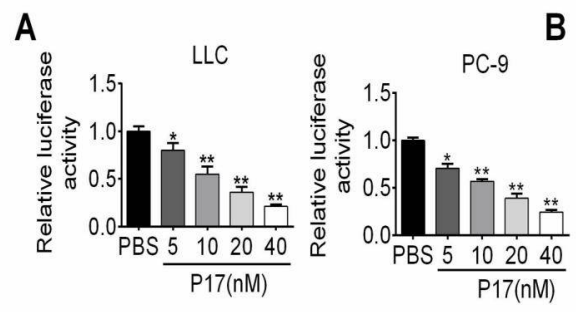

B
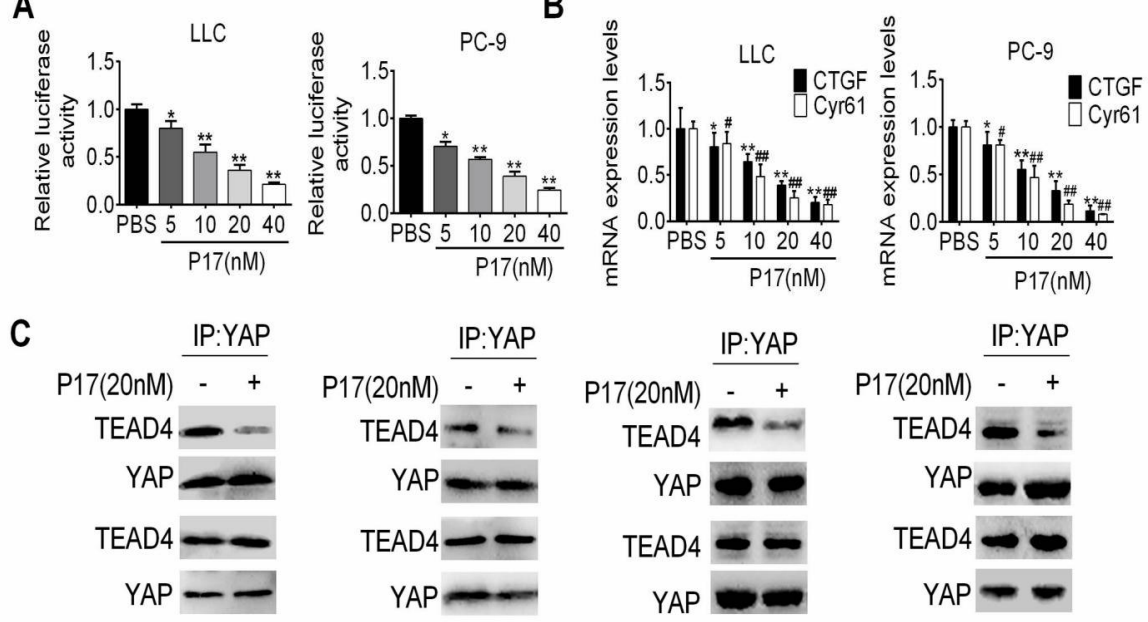

Figure 1: Peptide 17 efficiently disturbed the interaction of YAP and TEAD4 as well inhibited the expression of YAP downstream genes. (A) Luciferase reporter assay revealed that peptide 17 efficiently bound with TEAD4 in LLC and PC-9 cells. (B) RT-PCR results showed decreased expression of CTGF and Cyr61 in response to higher concentrations of peptide 17. (C) Co-immunoprecipitation assay directly demonstrated that peptide 17 efficiently disturbed the interaction of YAP and TEAD4; ${ }^{* *} p<0.001$, vs. control 


\section{Peptide 17 inhibits lung cancer cell proliferation}

The CCK8 assay showed a lower viability with increasing peptide concentration for LLC and PC-9 cells (Figure 2). In addition, clone formation assay also revealed that peptide 17 at the concentration of $40 \mathrm{nM}$ strongly inhibited LLC and PC-9 cells proliferation (Figure 3 A-B). Ki67, a proliferative marker of cells, was also downregulated after supplementation with peptide 17 (Figure 4).
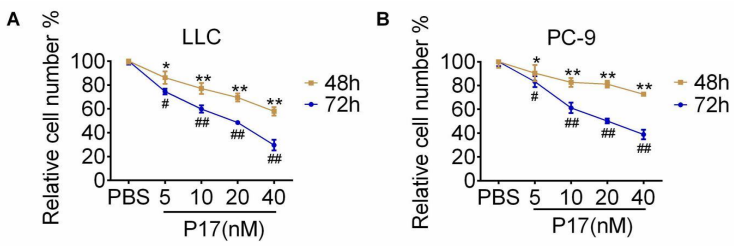

Figure 2: Peptide 17 efficiently restricted lung cancer cells viability. (A-B) CCK-8 assay revealed that LLC and PC- 9 cells viability was decreased with raised in a time-and concentration-dependent manner

A
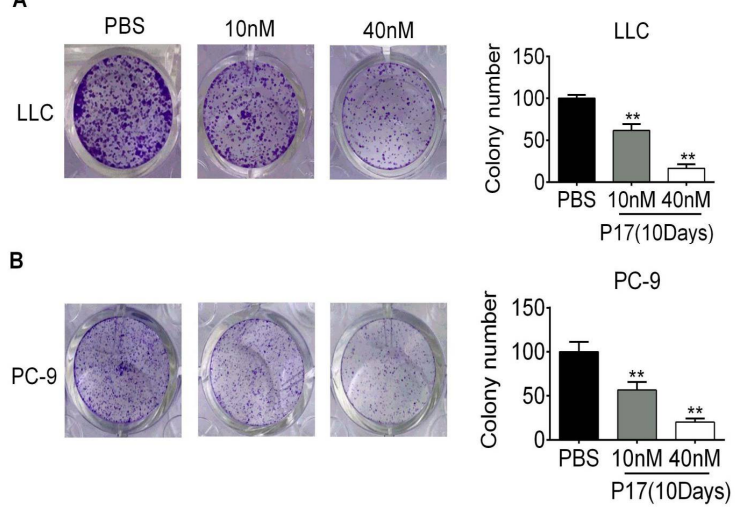

Figure 3: Peptide 17 efficiently inhibited lung cancer cells proliferation. (A) Clone formation assay revealed that a high concentration $(40 \mathrm{nM})$ of peptide 17 , compared to a lower concentration (10 nM), showed a strong inhibitory effect on LLC cell proliferation. (B) Clone formation assay also revealed that a high concentration (40 nM) of peptide 17 showed a strong inhibitory effect on PC-9 cell proliferation

\section{Peptide 17 promotes tumor cell apoptosis}

To assess whether peptide 17 affected LLC and PC-9 cell apoptosis, cells supplemented with peptide 17 for $24 \mathrm{~h}$ were collected. The apoptosis assay indicated that a larger proportion of apoptotic cells was observed in response to an increase of peptide concentration (Figure 5).

Further, the effect of drug consumption time on cell apoptosis was also tested. The results showed that the proportion of apoptotic lung cancer cells was increased with prolonged treatment with peptide 17 (Figure 6). The concentration of apoptosis associated proteins, including BAX, was also increased and further promoted lung cancer cell apoptosis in a timeand concentration-dependent manner (Figure 7).

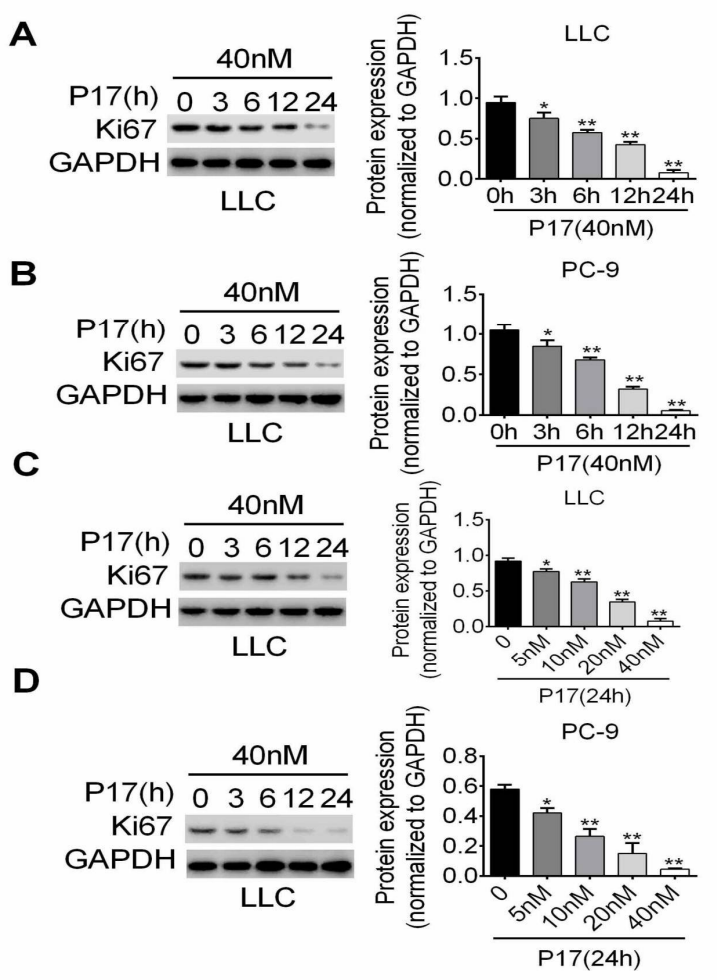

Figure 4: Effect of peptide 17 on expression of ki67 in lung cancer cells (A) Peptide 17, in a time-dependent manner, inhibited the expression of ki67 in LLC cells. (B) Peptide 17 inhibited the expression of ki67 in LLC cells in a time-dependent manner. (C) In LLC cells, peptide 17 efficiently inhibited ki67 expression in a dose-dependent manner. (D) Peptide 17, in a dosedependent manner, efficiently inhibited ki67 expression in PC9 cells.

\section{DISCUSSION}

Lung cancer, a devastating disease, was characterized by coughing, weight loss, weakness, fever and coughing up blood [15]. Chest radiograph, CT imaging and bronchoscopy were used to identify the type, extent, and histopathology of the disease [16]. For early stage lung cancer, surgery is the recommended treatment. About $70 \%$ of patients that received surgery survived more than 5 years. Surprisingly, drugs targeted for early stage lung cancer therapy, such as adjuvant bevacizumab, adjuvant epidermal growth factor receptor tyrosine kinase inhibitor (EGFR TKI) and ALK inhibitor, showed no obvious benefit [17]. For advanced lung cancer therapy, two regimens are recommended based on genetic mutations [18]. For example, patients who are not candidates for an approved molecular drug usually receive 
A
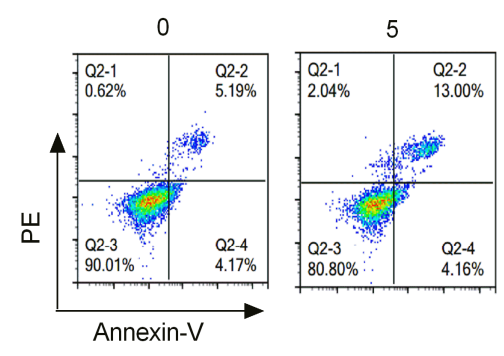

B
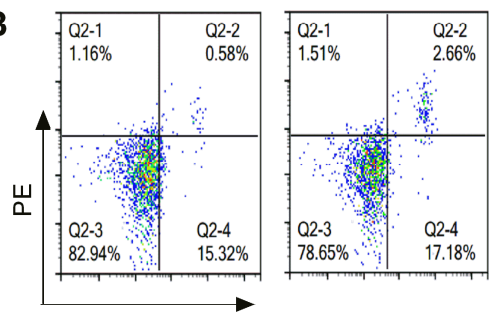

Annexin- $V$

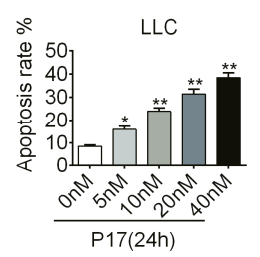

$\mathrm{P} 17(\mathrm{nM}, 24 \mathrm{~h})$
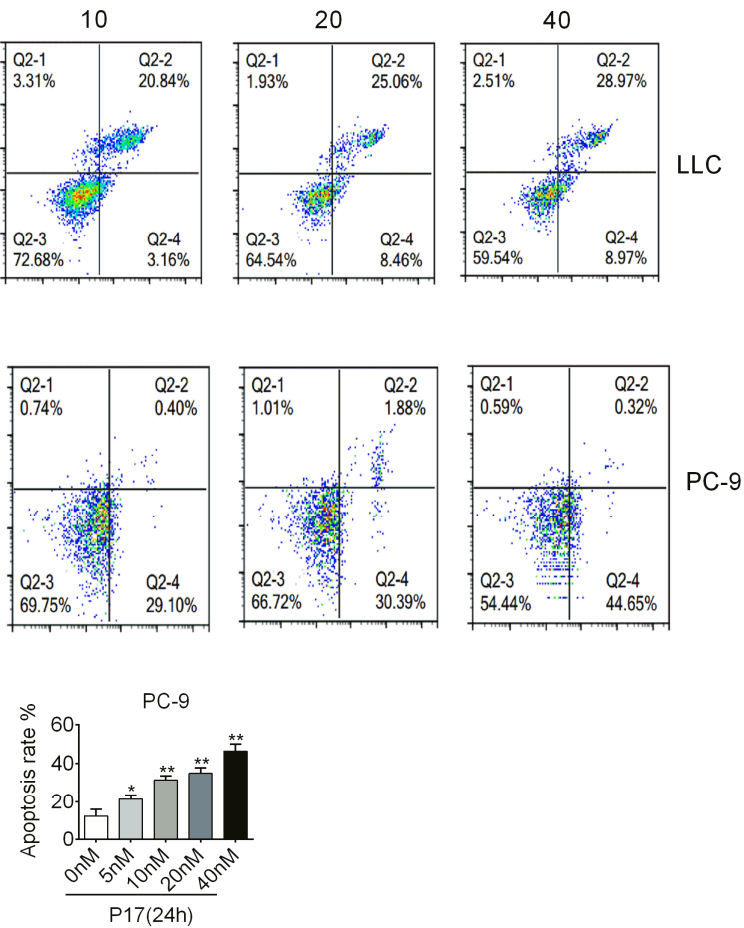

Figure 5: Peptide 17, in a concentration-dependent manner, facilitated lung cancer cell apoptosis. (A) In LLC cells, the proportion of apoptotic cells was elevated with rising concentrations of peptide 17. (B) In PC-9 cells, the proportion of apoptotic cells was also increased following rising concentrations of peptide 17. (C) Quantification of apoptotic cells after supplementation of peptide 17 in LLC and PC-9 cell cultures

A

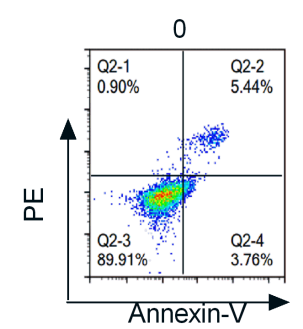

B

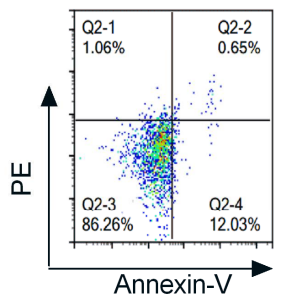

P17(h,40nM)
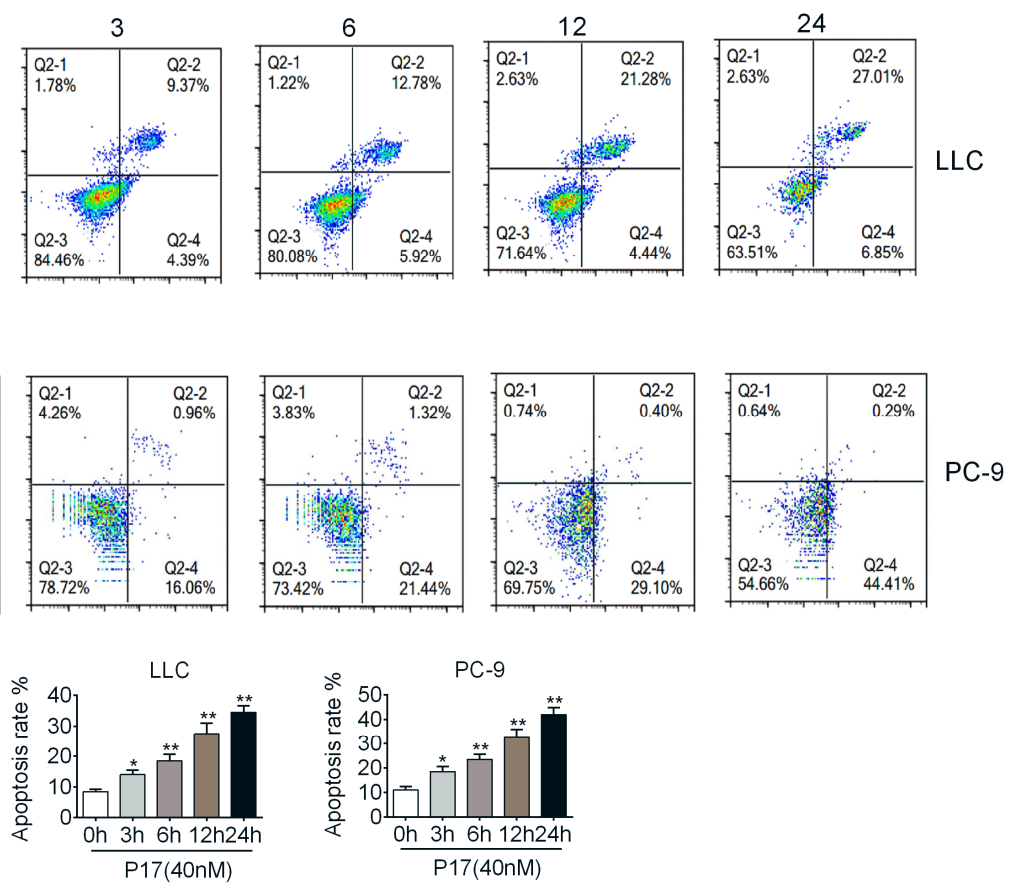

Figure 6: Following prolonged treatment with peptide 17, a larger population of lung cancer cells suffered from apoptosis. (A) In LLC cells, the proportion of apoptotic cells was elevated with prolonged treatment with peptide 17. (B) In PC-9 cells, the proportion of apoptotic cells was also increased in response to treatment with peptide 17. (C) Quantification of apoptotic cells after supplementation of peptide 17 in LLC and PC-9 cell cultures 
A
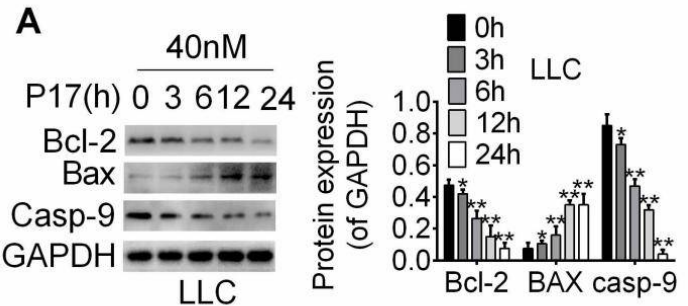

C
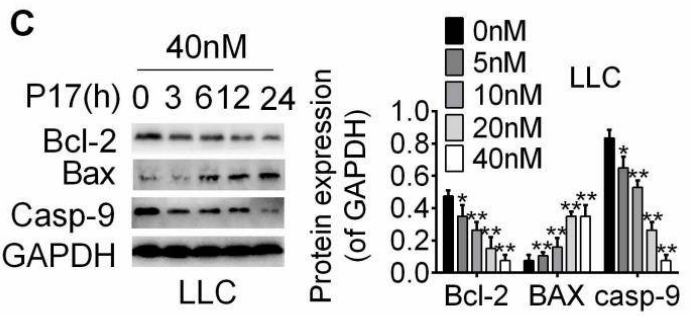

B
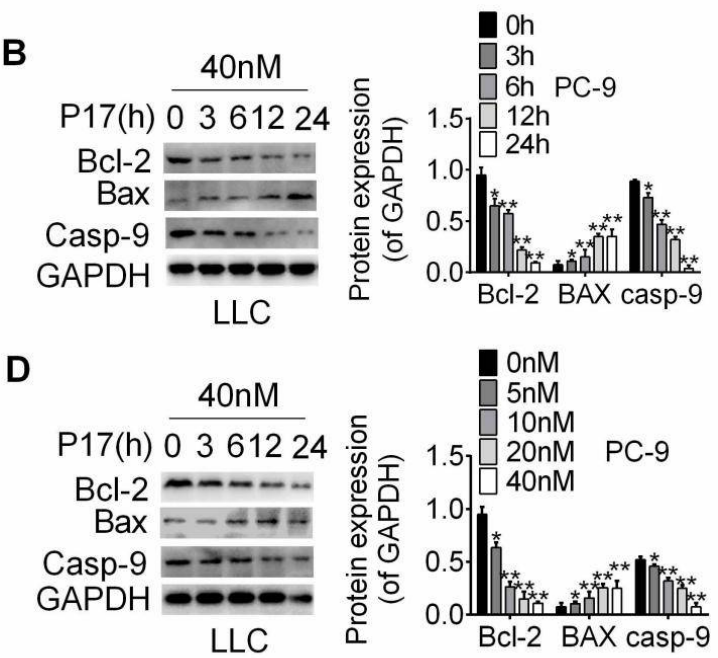

Figure 7: Bcl2/Bax/Caspase-9 signal mediated lung cancer cell apoptosis. (A-C) In LLC cells supplemented with peptide 17 (40 nM), western blot and RT-PCR results showed that Bcl2 / Bax / Caspase-9 signal was activated and that this effect was enhanced by increasing peptide concentration. (B-D) In PC-9 cells supplemented with peptide 17, western blot and RT-PCR results showed that Bcl2/Bax/Caspase-9 signal was also activated and that this effect was enhanced in a time dependent manner'

platinum-based therap. In contrast, patients with common gene abnormalities, such as EGFR, ALK, KRAS, and MET, are treated with the corresponding targeted inhibitors as an adjuvant therapy. The use of targeted drugs in advanced lung cancer has resulted in encouraging improvements in the overall survival rate. Unfortunately, there are still many patients with TKI resistance; therefore, other important molecular mechanisms urgently need to be investigated [19].

Recent studies showed that YAP is closely associated with lung cancers. There are at least three mechanisms of YAP function in lung cancers. First, YAP is essential to primary lung cancer cell proliferation. For example, Mao et al implied that YAP was critical to KRAS ${ }^{\mathrm{G} 12 \mathrm{D}}$ induced lung cancer [20]. YAP is expressed in the initial and later stages lung cancer. Deletion of YAP completely blocked KRAS ${ }^{\mathrm{G} 12 \mathrm{D}}$, as well as P53 loss-driven adenocarcinoma initiation and progress. Next, YAP is responsible for lung cancer cell migration and metastasis [21]. Sun et al. reported that tenascin- $C$ bound to the $\alpha 9 \beta 1$ receptor which is a type of intergrin and subsequently reduced the expression of YAP.. This signal cascade promoted lung cancer cells migration and invasion.

Finally, a high expression of YAP is closely associated with TKI resistance in lung cancer [22]. Given the important role of YAP in lung cancer cells, we subsequently examined the expression of YAP in LLC and PC-9 cells lines that originated from human lung cancer specimens. Results showed that YAP and its effector TEAD4 were highly expressed. Therefore, it is obvious that YAP signaling inhibitors would restore this effect. Several molecules have shown inhibitory effects on YAP. siRNAs have been designed to inhibit YAP activity [23], and YAP-like peptides without biological activity have been developed that show priority in combination with TEAD [14,24]. Other YAP inhibitors, for example statin, with restricted efficiency have also been applied to decrease lung cancer cell YAP expression [25].

Owing to the instability of nucleic acid drugs in vivo, peptide 17, a promising inhibitor that can efficiently disrupt the interaction between YAP and TEAD, was therefore investigated in lung cancer. Co-immunoprecipitation and luciferase reporter assay demonstrated the efficiency of peptide 17 in disturbing the YAP-TEAD4 interaction. In addition, peptide 17, at a concentration of $40 \mathrm{nM}$, was the most efficient in binding TEAD4. Intriguingly, we found target genes of YAP signaling, such as CCN1 (Cyr61) and CCN2 (CTGF), were both down-regulated. CCN1 / 2 has been reported to be closely associated with tumor cell proliferation, apoptosis, and migration [26,27]. Results showed that peptide 17 efficiently inhibited LLC and PC-9 cell proliferation and induced a larger portion of cells to undergo apoptosis.

\section{CONCLUSION}

Peptide 17 is a promising molecule for lung cancer treatment via inhibition of the interaction between YAP and TEAD. Furthermore, studies on the exact mechanism of YAP signaling in lung 
cancer would provide a clear insight for translational research and clinical treatment.

\section{DECLARATIONS}

\section{Conflict of Interest}

No conflict of interest associated with this work.

\section{Contribution of Authors}

We declare that this work was done by the authors named in this article and all liabilities pertaining to claims relating to the content of this article will be borne by the authors. Jie Jiang designed all the experiments and revised the paper. Heng Du, Jing Zhuang and Quyue Xu performed the experiments, and Heng Du, Yaping Gui, Li Zhu and Le Gao wrote the paper.

\section{REFERENCES}

1. Thiene GGB. Morgagni: De sedibus et causis morborum per anatomen indagatis. G Ital Cardiol 1985; 15(10): 1002-1003.

2. Obeid R, Pietrzik K. Smoking, B Vitamins, and Lung Cancer: The Chicken or the Egg Causality Dilemma. J Clin Oncol 2017; 36(6): 75-77.

3. Fajersztajn $L$, Veras $M$, Barrozo L, Saldiva P. Air pollution: a potentially modifiable risk factor for lung cancer. Nat Rev Cancer 2013; 13(9): 674-678.

4. Smith R, Andrews K, Brooks D, DeSantis C, Fedewa S, Lortet-Tieulent J, Manassaram-Baptiste D, Brawley OW, Wender RC. Cancer screening in the United States, 2016: A review of current American Cancer Society guidelines and current issues in cancer screening. CA Cancer J Clin 2016; 66(2): 96-114.

5. Romero $R$, Sayin $V$, Davidson $S$, Bauer $M$, Singh $S$, LeBoeuf $S$, Karakousi TR, Ellis DC, Bhutkar A, Sánchez-Rivera FJ, et al. Keap1 loss promotes Krasdriven lung cancer and results in dependence on glutaminolysis. Nat Med 2017; 23(11): 1362-1368.

6. Tan C, Gilligan D, Pacey S. Treatment approaches for EGFR-inhibitor-resistant patients with non-small-cell lung cancer. Lancet Oncol 2015; 16(9): e447-e459.

7. Camidge $D$, Pao $W$, Sequist $L$. Acquired resistance to TKIs in solid tumours: learning from lung cancer. Nat Rev Clin Oncol 2014; 11(8): 473-481.

8. Zhong $W$, Wang $Q$, Mao $W, X u S, W u L$, Shen $Y$, Liu YY, Chen $C$, Cheng $Y, X u L$, et al. Gefitinib versus vinorelbine plus cisplatin as adjuvant treatment for stage II-IIIA (N1-N2) EGFR-mutant NSCLC (ADJUVANT / CTONG1104): a randomised, open-label, phase 3 study. Lancet Oncol 2018; 19(1): 139-148.

9. Shaw A, Kim $T$, Crinò L, Gridelli $C$, Kiura K, Liu G, Novello S, Bearz A, Gautschi O, Mok T, et al. Ceritinib versus chemotherapy in patients with ALK-rearranged non-small-cell lung cancer previously given chemotherapy and crizotinib (ASCEND-5): a randomised, controlled, open-label, phase 3 trial. Lancet Oncol 2017; 18(7): 874-886.

10. Reck M, Rabe K. Precision Diagnosis and Treatment for Advanced Non-Small-Cell Lung Cancer. N Engl J Med 2017; 377(9): 849-861.

11. Zhao B, Kim J, Ye X, Lai Z, Guan K. Both TEAD-binding and $W W$ domains are required for the growth stimulation and oncogenic transformation activity of yes-associated protein. Cancer Res 2009; 69(3): 1089-1098.

12. Dong Q, Fu L, Zhao Y, Du Y, Li Q, Qiu X, Wang $E$. Rab11a promotes proliferation and invasion through regulation of YAP in non-small cell lung cancer. Oncotarget 2017; 8(17): 27800-27811.

13. Zhou Z, Hu T, Xu Z, Lin Z, Zhang Z, Feng T, Zhu L, Rong $Y$, Shen $H$, Luk JM, et al. Targeting Hippo pathway by specific interruption of YAP-TEAD interaction using cyclic YAP-like peptides. FASEB J 2015; 29(2): 724732.

14. Zhang Z, Lin Z, Zhou Z, Shen H, Yan S, Mayweg A, Xu $Z$, Qin N, Wong JC, Zhang Z, et al. Structure-Based Design and Synthesis of Potent Cyclic Peptides Inhibiting the YAP-TEAD Protein-Protein Interaction. ACS Med Chem Lett 2014; 5(9): 993-998.

15. Fairchild A, Harris K, Barnes E, Wong R, Lutz S, Bezjak $A$, Cheung $P$, Chow E. Palliative thoracic radiotherapy for lung cancer: a systematic review. J Clin Oncol 2008; 26(24): 4001-4011.

16. Lizama C, Slavova-Azmanova N, Phillips M, Trevenen M, $\mathrm{Li} I$, Johnson C. Implementing Endobronchial Ultrasound-Guided (EBUS) for Staging and Diagnosis of Lung Cancer: A Cost Analysis. Med Sci Monit 2018; 24: 582-589.

17. Sgambato A, Casaluce F, Maione P, Gridelli C. Targeted therapies in non-small cell lung cancer: a focus on ALK/ROS1 tyrosine kinase inhibitors. Expert Rev Anticancer Ther 2018; 18(1): 71-80.

18. Hirsch F, Scagliotti G, Mulshine J, Kwon R, Curran W, $W u Y$, Paz-Ares L. Lung cancer: current therapies and new targeted treatments. Lancet 2017; 389(10066): 299-311.

19. Lin J, Riely G, Shaw A. Targeting ALK: Precision Medicine Takes on Drug Resistance. Cancer Discov 2017; 7(2): 137-155.

20. Mao $Y$, Sun S, Irvine $K$. Role and regulation of Yap in KrasG12D-induced lung cancer. Oncotarget 2017; 8(67):110877-110889.

21. Hao F, Xu Q, Zhao Y, Stevens J, Young S, Sinnett-Smith $J$, Rozengurt E. Insulin Receptor and GPCR Crosstalk Stimulates YAP via PI3K and PKD in Pancreatic Cancer Cells. Mol Cancer Res 2017; 15(7): 929-941.

22. Lin C, Pelissier F, Zhang H, Lakins J, Weaver V, Park C, LaBarge MA. Microenvironment rigidity modulates responses to the HER2 receptor tyrosine kinase inhibitor lapatinib via YAP and TAZ transcription factors. Mol Biol Cell 2015; 26(22): 3946-3953.

23. Tanaka K, Osada H, Murakami-Tonami Y, Horio Y, Hida $T$, Sekido Y. Statin suppresses Hippo pathway- 
inactivated malignant mesothelioma cells and blocks the YAP / CD44 growth stimulatory axis. Cancer Lett 2017; 385: 215-224.

24. Kang $W$, Huang $T$, Zhou $Y$, Zhang J, Lung $R$, Tong J, Chan AWH, Zhang B, Wong CC, Wu F, et al. miR-375 is involved in Hippo pathway by targeting YAP1/TEAD4-
CTGF axis in gastric carcinogenesis. Cell Death Dis 2018; 9(2): 92-108.

25. Hsu Y, Hung J, Chou S, Huang M, Tsai M, Lin Y, Chiang SY, Ho YW, Wu CY, Kuo PL. Angiomotin decreases lung cancer progression by sequestering oncogenic YAP / TAZ and decreasing Cyr61 expression. Oncogene 2015; 34(31): 4056-4068. 